\title{
INFLUENCE OF pH ON THE EFFECT OF PILOCARPINE ON AQUEOUS DYNAMICS* ${ }^{\dagger}$
}

\author{
BY \\ R. A. ANDERSON \\ Department of Pharmacy \\ AND \\ J. B. COWLE \\ Glaucoma Research Laboratories, Department of Ophthalmology and Eye Health, \\ University of Sydney, Australia
}

PILOCARPINE eye-drops are usually dispensed in acid solution to prevent appreciable degradation of the alkaloid during sterilization and storage. However, such solutions are considered to cause greater irritation than partly neutralized solutions. On account of this Riegelman and Vaughan (1958) have suggested that pilocarpine solutions buffered to pH 6.8 may be preferred by patients, even though these solutions are less stable and need to be renewed frequently. Solutions buffered to near-neutrality might be expected also to be more active if dilution and loss of drug from excessive lacrimation were reduced, and also because more drug would be present as uncharged free base which would favour transport through the cornea to the site of action. Previous attempts to demonstrate increased activity in less acid solutions have been inconclusive (Floyd, Kronfeld, and McDonald, 1953; Riegelman and Vaughan, 1958).

In the present investigation a single-drop technique similar to that of Kronfeld (1964) has been used in patients to examine the dose-response relationships by tonography with pilocarpine solutions at $\mathrm{pH} 4$ and $\mathrm{pH} 6.5$ and with solutions of the trans-isomer isopilocarpine at $\mathrm{pH} 4$.

\section{Methods}

\section{Test Solutions}

Isopilocarpine hydrochloride was prepared by the method of Wojciechowski and Ecanow (1961). This compound and pilocarpine hydrochloride $(\mathrm{BDH})$ were used to prepare $0 \cdot 5,1 \cdot 0,2 \cdot 0,4 \cdot 0$, and 8.0 per cent. solutions containing 0.002 per cent. phenylmercuric nitrate. These solutions had a $\mathrm{pH}$ value of about 4. Another series of pilocarpine solutions of the same concentrations was prepared containing sufficient borax to increase the $\mathrm{pH}$ to 6.5 . The $0.5,1.0$, and 2.0 per cent. solutions were adjusted by the addition of sodium chloride to render them isotonic with tear fluid. Solutions were sterilized by membrane filtration and renewed at intervals of one week for the buffered solutions and about monthly for the acidic solutions.

\section{Pressure Measurements and Outflow Facility Determinations}

The steady-state intra-ocular pressure $\left(P_{o}\right)$ and facility of outflow $(C)$ were determined from tonography tracings recorded using a Schwartzer electronic tonometer. The tracings were analysed without corrections for scleral rigidity and a small number were discarded on account of irregularities.

\footnotetext{
* Received for publication August 11, 1967.
}

† Address for reprints: R. A. Anderson, Department of Pharmacy, University of Sydney, Australia. 
Seventeen patients were used in this investigation who were diagnosed at the Glaucoma Clinic as having chronic simple glaucoma with open angles. Where necessary, treatment was suspended for one week before the investigation. Before using the drugs a number of tonographic tracings were recorded from each patient to determine the intra-ocular pressure and the outflow facility of each eye in the untreated state. Tonographic tracings were again recorded after the application of drugs at the different dose levels in both eyes of each patient. The doses were administered as a single drop of $0.04 \mathrm{ml}$. into the conjunctival sac at weekly intervals at $8.0 \mathrm{a} . \mathrm{m}$. and tracings were made 4 hours later.

The outflow facility response has been calculated as the ratio of the outflow facility value of the treated eye $\left(C_{d}\right)$ to the mean value of the untreated eye $(C)$. The pressure response has been calculated as the ratio of the intra-ocular pressure of the treated eye $\left(\boldsymbol{P}_{o_{d}}\right)$ to the mean value of the intra-ocular pressure of the untreated eye $\left(P_{o}\right)$.

\section{Pilocarpine Determinations in Tear Fluid}

The influence of tear fluid on the concentration of pilocarpine after instillation of 4 per cent. (isotonic) solutions at $\mathrm{pH} 4$ and 6.5 was investigated in thirteen patients. Into one eye of each patient was instilled $0.04 \mathrm{ml}$. of solution at $\mathrm{pH} 4$ and into the other eye an equal volume of the solution adjusted to $\mathrm{pH} 6.5 ; 30$ seconds after instillation the tear fluid was collected by absorption onto weighed filter-paper strips. The collection was continued over a period of 30 seconds. The strips were immediately reweighed to find the quantity of tear fluid collected. A drop of $0 \cdot 1 \mathrm{~N} \mathrm{HCl}$ was added to prevent decomposition of alkaloid. The pilocarpine was eluted from each paper strip with $0.01 \mathrm{~N} \mathrm{HCl}$, and the amount of alkaloid determined by spectrophotometric analysis at $215 \mathrm{~m} \mu$.

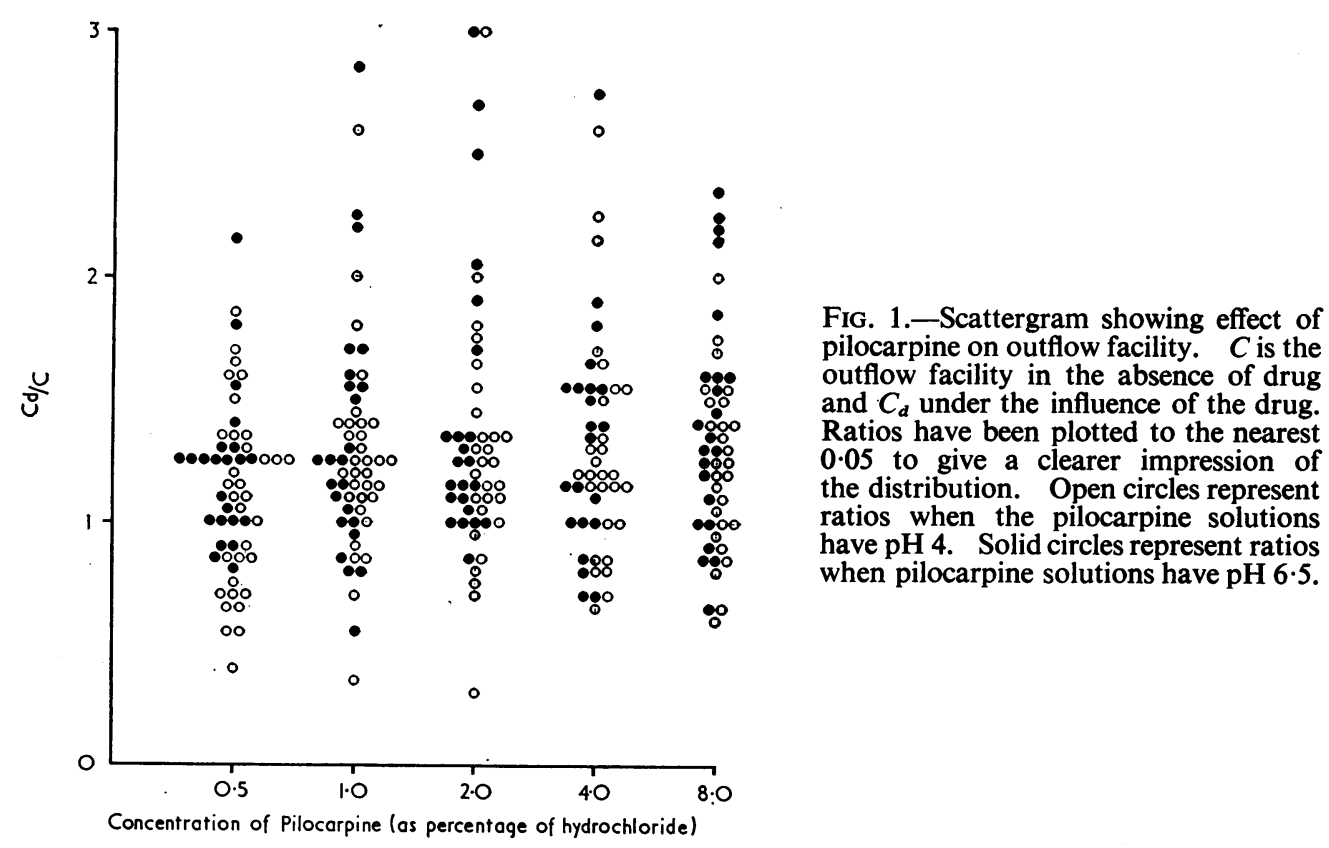

\section{Results}

Scattergrams of the pressure and outflow responses to each of the pilocarpine solutions are shown in Fig. 1 (above) and in Fig. 2 (opposite). 


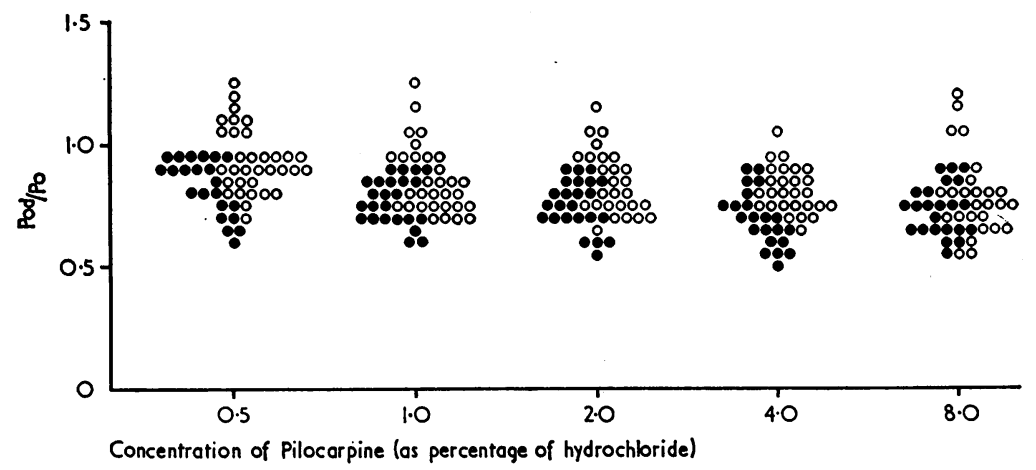

Fig. 2.-Scattergram showing effect of pilocarpine on intra-ocular pressure. $P_{o}$ is the intra-ocular pressure in the absence of drug and $\boldsymbol{P}_{o_{d}}$ under the influence of drug. Ratios have been plotted to the nearest 0.05 to give a clearer impression of the distribution. Open circles represent ratios when the pilocarpine solutions have pH 4. Solid circles represent ratios when pilocarpine solutions have pH 6.5.

The mean values with standard errors of the responses to each dose level of the pilocarpine and isopilocarpine solutions are shown in Table I and in Table II (overleaf).

TABLE I

EFfect of Pilocarpine and Isopilocarpine on OUtFlow Facility

\begin{tabular}{|c|c|c|c|c|}
\hline \multicolumn{2}{|l|}{ Drug } & $\begin{array}{l}\text { Concentration } \\
\text { (per cent.) }\end{array}$ & $\begin{array}{l}\text { Mean Response* } \\
\text { as } C_{d} /_{C}\end{array}$ & $\begin{array}{c}\text { Standard Error } \\
\text { of Mean }\end{array}$ \\
\hline \multicolumn{2}{|l|}{$\begin{array}{l}\text { Isopilocarpine } \\
\text { Hydrochloride }\end{array}$} & $\begin{array}{l}0.5 \\
1.0 \\
2.0 \\
4.0 \\
8.0\end{array}$ & $\begin{array}{l}1.10(31) \\
1.04(31) \\
1.06(31) \\
1.03(34) \\
1.06(32)\end{array}$ & $\begin{array}{l}0.056 \\
0.053 \\
0.060 \\
0.052 \\
0.071\end{array}$ \\
\hline \multirow{2}{*}{$\begin{array}{l}\text { Pilocarpine } \\
\text { Hydrochloride }\end{array}$} & pH 4 & $\begin{array}{l}0.5 \\
1.0 \\
2.0 \\
4.0 \\
8.0\end{array}$ & $\begin{array}{l}1.09(33) \\
1.25(32) \\
1.27(28) \\
1.30(28) \\
1.23(27)\end{array}$ & $\begin{array}{l}0.066 \\
0.066 \\
0.093 \\
0.087 \\
0.065\end{array}$ \\
\hline & pH 6.5 & $\begin{array}{l}0.5 \\
1.0 \\
2.0 \\
4.0 \\
8.0\end{array}$ & $\begin{array}{l}1.23(22) \\
1.35(24) \\
1.42(24) \\
1.35(22) \\
1.43(23)\end{array}$ & $\begin{array}{l}0.065 \\
0.107 \\
0.121 \\
0.102 \\
0.099\end{array}$ \\
\hline
\end{tabular}

* Number of values from which mean was calculated are shown in parentheses.

The dose-response relationships for the pressure reducing effect of the pilocarpine solutions are shown in Fig. 3 (overleaf) with the dose increments on a logarithmic scale.

The concentrations of pilocarpine in samples of tear fluid recovered after instillation of the test solutions are shown in Table III (overleaf).

\section{Discussion}

The data in Tables I and II show the absence of any appreciable effect of isopilocarpine on intra-ocular pressure and outflow facility. This isomer has the trans configuration and chemically is the more stable form. Pilocarpine is converted to isopilocarpine under certain conditions and this results in loss of effectiveness. 
TABLE II

Effect of Pilocarpine and Isopilocarpine on InTra-ocular Pressure

\begin{tabular}{|c|c|c|c|c|}
\hline \multicolumn{2}{|c|}{ Drug } & $\begin{array}{c}\text { Concentration } \\
\text { (per cent.) }\end{array}$ & $\begin{array}{c}\text { Mean Response* } \\
\text { as }\left.P_{o_{d}}\right|_{P o}\end{array}$ & $\begin{array}{l}\text { Standard Error } \\
\text { of Mean }\end{array}$ \\
\hline \multicolumn{2}{|c|}{$\begin{array}{l}\text { Isopilocarpine } \\
\text { Hydrochloride }\end{array}$} & $\begin{array}{l}0.5 \\
1.0 \\
2.0 \\
4 \cdot 0 \\
8 \cdot 0\end{array}$ & $\begin{array}{l}0.98(31) \\
0.96(31) \\
0.93(31) \\
1.01(34) \\
1.00(32)\end{array}$ & $\begin{array}{l}0.021 \\
0.026 \\
0.023 \\
0.016 \\
0.021\end{array}$ \\
\hline \multirow{2}{*}{$\begin{array}{c}\text { Pilocarpine } \\
\text { Hydro- } \\
\text { chloride }\end{array}$} & pH 4 & $\begin{array}{l}0 \cdot 5 \\
1 \cdot 0 \\
2 \cdot 0 \\
4 \cdot 0 \\
8 \cdot 0\end{array}$ & $\begin{array}{l}0.94(33) \\
0.87(32) \\
0.85(28) \\
0.83(28) \\
0.79(27)\end{array}$ & $\begin{array}{l}0.023 \\
0.025 \\
0.026 \\
0.020 \\
0.031\end{array}$ \\
\hline & pH 6.5 & $\begin{array}{l}0.5 \\
1.0 \\
2.0 \\
4.0 \\
8.0\end{array}$ & $\begin{array}{l}0.83(22) \\
0.78(24) \\
0.75(24) \\
0.70(22) \\
0.74(23)\end{array}$ & $\begin{array}{l}0.025 \\
0.019 \\
0.020 \\
0.024 \\
0.020\end{array}$ \\
\hline
\end{tabular}

* Number of values from which mean was calculated are shown in parentheses.

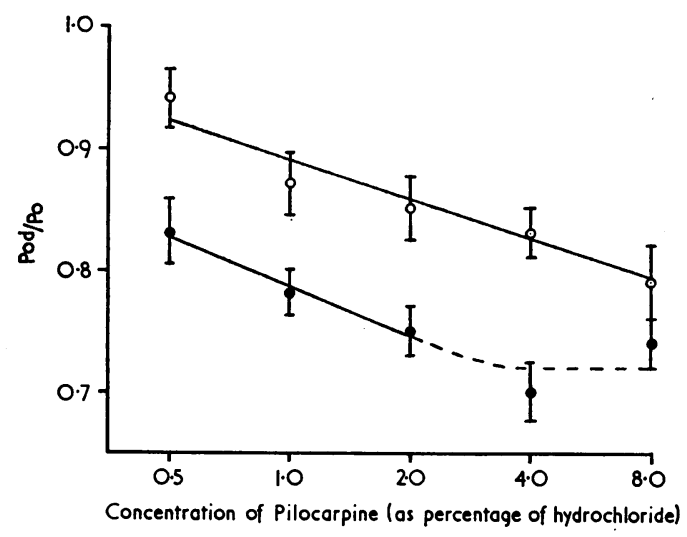

Fig. 3.-Effect of pilocarpine on intra-ocular pressure response. Open circles represent mean responses when pilocarpine solutions have $\mathrm{pH} 4$. Solid circles represent mean responses when pilocarpine solutions have pH $6 \cdot 5$. Vertical bars represent plus or minus one standard error of mean. Regression lines do not include data for 4 and 8 per cent. solutions at pH 6.5.
TABLE III

Concentration of Pilocarpine in SOLUTIONS RECOVERED AFTER INSTILLATION OF 4 PER CENT. SOLUTIONS

\begin{tabular}{c|c|c}
\hline \multirow{2}{*}{ Subject No. } & \multicolumn{2}{|c}{$\begin{array}{c}\text { Percentage as } \\
\text { Pilocarpine Hydrochloride }\end{array}$} \\
\cline { 2 - 3 } & pH 6.5 & pH 4 \\
\hline 1 & 2.11 & 2.77 \\
2 & 1.69 & 1.92 \\
3 & 3.20 & 2.95 \\
4 & 3.79 & 3.61 \\
5 & 1.93 & 1.39 \\
6 & 3.61 & 3.51 \\
7 & 1.52 & 1.34 \\
8 & 2.94 & 1.53 \\
9 & 0.98 & 1.98 \\
10 & 3.12 & 0.82 \\
11 & 1.05 & 1.22 \\
12 & 2.74 & 2.05 \\
13 & 3.30 & 2.09 \\
\hline Mean & 2.46 & 2.09 \\
\hline
\end{tabular}

The outflow facility responses to pilocarpine recorded in Fig. 1 show a wide scatter. The statistics in Table I confirm that, although the mean outflow responses for solutions of $\mathrm{pH} 6.5$ are greater than for solutions at $\mathrm{pH} 4$, the scatter is so great that the differences are not significant.

As would be expected the intra-ocular pressure measurements are more precise than the outflow facility determinations (Fig. 2 and Table II). For the pH 4 pilocarpine solutions, the pressure decrement is approximately proportional to the logarithm of the concentration 
and a regression line has been drawn in Fig. 3. A similar relationship is found for the near-neutral solutions at the lower concentrations, and the regression line for the $0 \cdot 5,1$, and 2 per cent. data has about the same slope as the $\mathrm{pH} 4$ line. The responses to the less acidic solutions are greater than for corresponding concentrations at $\mathrm{pH} 4$, but level off at a concentration of about 2 to 4 per cent. The increases in potency of the pH 6.5 pilocarpine solutions over the more acid solutions are significant $(P<0.01)$ for the $0.5,1,2$, and 4 per cent. concentrations. Although, at the 8 per cent. concentration, the near-neutral solution also shows greater potency than the $\mathrm{pH} 4$ solution, the difference is not significant $(\mathrm{P}=0 \cdot 1-0 \cdot 2)$.

These findings show that marked increases in potency are possible when pilocarpine solutions are partly neutralized. The 0.5 per cent. solution when adjusted to $\mathrm{pH} 6.5$ produces an ocular hypotensive effect approximately equivalent to a 4 per cent. solution of pilocarpine hydrochloride at the more usual $\mathrm{pH} 4$. Although the chemical stability of pilocarpine is reduced at higher $\mathrm{pH}$ values, further evaluation of the effectiveness of nearneutral solutions in the clinical treatment of glaucoma patients appears to be warranted.

The increased responses to the near-neutral solutions may be due to two factors. At the lower $\mathrm{pH}$, a greater proportion of the drug is present as the protonated form, and this charged species would not be expected to penetrate the corneal membrane as readily as the un-ionized molecule. In addition, the smaller responses to the acidic solutions may be due to increased flow of tear fluid caused by the more irritant effect of these solutions. The results set out in Table III show that, although the more acidic solution may cause increased lacrimation and increased dilution of alkaloidal solution, the differences are far too small to account for the increased potency of near-neutral pilocarpine solutions. Consequently it is suggested that the principal reason for increased potency of pilocarpine solutions at $\mathrm{pH} 6.5$ is the much greater proportion of drug in the form of the uncharged alkaloidal base, which more readily penetrates the cornea.

\section{Conclusion}

Pilocarpine solutions at $\mathrm{pH} 6.5$ have a greater ocular hypotensive effect in glaucoma patients than solutions at $\mathrm{pH} 4$. Although the near-neutral solutions are less stable and would need to be renewed more frequently, further evaluation of their effectiveness in the treatment of glaucoma patients appears to be warranted.

We are indebted to Miss Elizabeth Hain and Miss Carmel O'Brien for technical assistance.

\section{REFERENCES}

Floyd, G., Kronfeld, P. C., and McDonald, J. E. (1953). J. Amer. pharm. Ass., sci. Ed., $42,333$. Kronfeld, P. C. (1964). Invest. Ophthal., 3, 258.

Riegelman, S., and Vaughan, D. G. (1958). J. Amer. pharm. Ass., pract. Pharm. Ed., 19, 474; $537 ; 665$. Wojciechowski, N. J., and Ecanow, B. (1961). J. pharm. Sci., 50, 887. 